\title{
Raising Interest in STEM Education: A Research-based Community College- University Partnership for Improving Minority Participation
}

\author{
Mr. Daniel Christe, Drexel University (Eng. \& Eng. Tech.)
}

Daniel Christe is pursuing concurrent Bachelor's and Master's degrees in Materials Science and Mechanical Engineering, respectively at Drexel University in Philadelphia Pennsylvania. His research interests center on predictive design of functional fabrics that "see, hear, sense, and adapt" to their environments. Daniel is currently a member of the Theoretical \& Applied Mechanics Group, within Drexel University's Mechanical Engineering \& Mechanics Department. He has also held a research appointment at the Department of Energy's Los Alamos National Laboratory in New Mexico. Augmenting his scientific interests, Daniel serves as a STEM educator working to improve minority representation in STEM through high-impact research experiences. As an Innovation Advisor to Elsevier's Academic Engineering Solutions Library Advisory Board (AES-LAB), he partners with librarians to create democratized approaches to 21 st century information literacy education on a global scale,

\section{Mr. Brian J Wisner, Drexel University}

Brian is a PhD Candidate in the Department of Mechanical Engineering and Mechanics at Drexel University. Brian received his bachelor's degrees in Mechanical Engineering and Physics in 2011 from Widener University and his Master's in 2013 from Drexel University. He then spent a year working at Piasecki Aircraft Corporation during which time he taught classes at Widener University as an Adjunct Instructor. In 2014 he returned to Drexel University and joined the Theoretical and Applied Mechanics Group under Dr. Antonios Kontsos. His research focuses on the identification of damage precursors in light metal alloys through the combination of nondestructive evaluation techniques including digital image correlation and acoustic emission monitoring coupled with in situ microstructure observation. Brian has been fortunate to be able to perform his work in collaboration with groups from Sandia National Labs and NASA Langley Research Center.

\section{Mr. Jay J. Bhatt, Drexel University (Eng. \& Eng. Tech.)}

Jay Bhatt is responsible for building library collections in engineering subject areas, outreach to faculty and students, and teaching information and research skills to faculty and students in Engineering, Biomedical Engineering, and related subject areas. He provides individual and small group consultations to students, instructional sessions to specific classes, online research support in both face to face and distance learning programs, and conducts workshops for specialized research areas. Jay is actively involved with the Engineering Libraries Division of the American Society for Engineering Education

\section{Dr. Antonios Kontsos, Drexel University}

Antonios Kontsos joined the Mechanical Engineering \& Mechanics Department at Drexel University in September 2009 and he is currently the Director of the Theoretical and Applied Mechanics Group (TAMG). He received his undergraduate 5-year Diploma (2002) from the Department of Mechanical Engineering and Aeronautics at University of Patras (Greece), and his MS (2005) and PhD (2007) degrees from the Department of Mechanical Engineering and Materials Science at Rice University (Houston, TX). He also held a 2-year Post-doc position at the Center for Mechanics of Solids, Structures and Materials in the Aerospace Engineering \& Engineering Mechanics Department at the University of Texas at Austin (Austin, TX). Kontsos is a member of the ASME, ASNT and Sigma Xi societies and he is serving as the Faculty Advisor of the local ASME student chapter at Drexel University 


\title{
Raising Interest in STEM Education (RISE): A Research-based Learning Approach for Improving Minority Participation in STEM
}

\begin{abstract}
Despite recent efforts, the fraction of underrepresented minorities employed in STEM fields mismatches the current demographics of the United States (U.S). In this context and over the past two years, an educational program between the Community College of Philadelphia and Drexel University with the overall objective to increase the interest of underrepresented minority students (URMs) in STEM has been implemented. The working hypothesis for the University component of this effort has been that learning about science and engineering is most effective if it is paired with the challenge of independent research in a collaborative "micro-environment", such as the one in academic research laboratories. In this approach, six undergraduate URMs (three male, three female) were selected in the inaugural year, expanding to eight students (four male, four female) in the program's second year. Each student selected a faculty advisor and research group aligned to their individual interests within the first week of the ten week program. From the outset, students were introduced to key library professionals and digital search tools which they employed to review literature relevant to their research foci, forming a basis for research proposals. By week four, students presented their research plans before a panel of faculty and student judges. To enrich individual research experiences, weekly seminars with guest lectures and discussions on modern drivers of STEM research were integrated in this summer research program. In order to complete the program, each student produced three final deliverables - an oral presentation, a technical poster and a final paper. In addition, students were exposed to an industrial R\&D setting through a visit to a multinational corporation known for its innovation. A final survey and individualized assessments were conducted to evaluate the effectiveness of the program and progress of the individual students, respectively. Students demonstrated familiarity with basic research methods and universally reported increased interest in STEM education and careers, with several continuing to work in their labs beyond the program's formal duration.
\end{abstract}

Keywords - Research-based Learning, Community Colleges, Minority Participation 


\section{Introduction}

Despite efforts, underrepresented minority (URM) and female students are disproportionately represented in STEM disciplines based on their fraction in United States demographics. Females and URMs face unique challenges in STEM compared with their white male peers, which need to be understood to drive an increase in their representation in this labor market segment. With minority groups currently accounting for the fastest growing segment of the U.S. population ${ }^{(1-3)}$, American global technical leadership and economic vitality will increasingly depend on minority demographics succeeding in science and technology fields ${ }^{(4)}$. However, minority and female students face particular challenges in university settings, often finding themselves one among few, if any, in STEM courses (5). Freshman and sophomore "gateway" courses typical of STEM programs often produce high attrition rates overall, disproportionately impacting minority and female students ${ }^{(6)}$. In many cases, minority students are often the first in their families to attend college, tend to come from lower-income households ${ }^{(6,7)}$, and speak English as a second language ${ }^{(6)}$. Such factors may lead to academic under-preparation and create intimidating situations upon arriving in collegiate settings ${ }^{(6)}$. These factors further produce a certain stigmatization which can deflate self-confidence and diminish academic performance ${ }^{(7)}$. In this context, tailored interventions can mitigate these negative factors to improve minority STEM participation.

Community colleges (CCs) play a vital role in the STEM education landscape and American higher education in general, serving nearly half of the United States' undergraduate students ${ }^{(8)}$, especially minorities. In fact, females and URMs are more likely to enter higher education through CCs, making them ideally positioned to equip targeted students with the knowledge, skills and support to successfully transition to four-year universities ${ }^{(9-11)}$. CC-University type partnerships can further enhance this preparation, extending high impact, undergraduate research experiences to $\mathrm{CC}$ students who would otherwise not have such opportunities, at critical course junctures.

The transfer pathway between CCs and Universities is fraught with challenges, especially for minority students. Overall, students who enter higher education in CCs are 15-20\% less likely to attain a bachelor's degree than their counterparts beginning in four-year institutions ${ }^{(11,12)}$. In fact, transfer students from CCs to typical Bachelor's granting 4-year institutions experience a wellknown transfer shock when entering the university environment, which may lead to a drop in self- 
confidence and academic performance within the first year of university studies ${ }^{(9,13-18)}$. Viewed through the lenses of transfer students, universities tend to have a "chilly", "competitive" atmosphere compared with the supportive environment of a community college. Negative faculty and staff attitudes on the abilities and qualifications of transfer students may further contribute to this perception ${ }^{(9)}$. Therefore, the importance of the first transfer year cannot be understated - if transfer students are able to navigate the initial transfer shock, they are just as likely to attain a bachelor's degree as their peers who attended four-year institutions from the outset ${ }^{(19)}$. In several cases, it has been actually shown that CC transfer students may even academically outperform their peer group ${ }^{(11,15)}$.

Mentoring, advising, and peer support in the CCs and universities are key instruments for successful transfers. According to recent reports ${ }^{(20)}$, the earlier students are exposed to the university environment, the better they will be able to deal with the challenges of transferring. Therefore, CC-University partnerships could potentially further enhance this preparation, extending resources typically available only to university students to $\mathrm{CC}$ students through undergraduate research interventions and university faculty/staff interactions.

Undergraduate research experiences have well-known positive impacts for all students, which are further amplified in the case of minority and female students ${ }^{(7,20,21)}$. In fact, the first of the 1998 Boren Commission's fifteen recommendations ${ }^{(22)}$ for the modern American research university was to "make research-based learning the standard" from the first year, envisioning education as an active inquiry-based process with faculty mentoring of students. Mentoring by faculty and graduate students and professional staff is indeed a particularly strong positive element of undergraduate research experiences ${ }^{(1,17,21,23)}$, giving students the identification and confidence needed to drive advanced education and career decisions related to STEM professions. Undergraduate research experiences often spark interests that subsequently translate to scientific careers ${ }^{(21,24-26)}$. In addition, targeted cohorts can gain guided exposure to the university environment while acquiring self-confidence through meeting the challenges of independent research. When students realize the meaningful contributions they can make to science/engineering, they potentially obtain extra motivation to further pursue STEM education and careers. 
This article expands the findings previously reported ${ }^{(27)}$ from the first year of implementing a CCUniversity STEM pilot program, and focuses on the collective results from a survey conducted by students from the two cohorts that participated in the first two years of the program. The results and discussion are presented solely from the perspective of the summer research program implemented by the University partner in this collaborative effort, and are used as a starting point for a comparative analysis of the program's structure which can lead to further improvements in the third and last year of this funded STEM project.

\section{Objectives Approach and methods}

The Raising Interest in STEM Education (RISE) program was structured to create an engaging, hands-on, and supportive STEM learning environment targeting URM and females based on the premise that STEM learning is most effective if paired with the challenge of conducting independent research. The research experience was implemented through a collaborative partnership between Community College of Philadelphia and Drexel University. Philadelphia is among the most impoverished large school districts in the U.S., predominantly serving minorities. Only 1 in 10 graduates from the Philadelphia School District earn a four-year college degree within ten years of graduation ${ }^{(28)}$, illustrating the vast opportunity for improvement. CCP has a total enrollment of approximately 34,300 (76\% minority), with $70 \%$ of first year students qualifying for Pell grants ${ }^{(29)}$, making it an ideal focus institution for minority and female improvement in STEM fields. The partner institution Drexel University is a mid-size private research university with a full-time enrollment of 13,000 students and strong emphasis placed on experiential learning in the form of a large cooperative education program (co-op).

In the program's first year ${ }^{(27)}$, six URMs (3 male, 3 female) were drawn from a pool of over twenty applicants. For the program's second year, eight URMs (four male, four female) were selected according to a more elaborate application process to assist the selection of the participating students. Specifically, all eligible applicants (again more than twenty) were: i) enrolled in an engineering or science program at the $\mathrm{CC}$, ii) had already completed core math and science courses, and iii) met a 2.5 minimum GPA requirement. Applicants were further required to write an essay stating their motivations for participating in the program and to obtain a letter of recommendation from a CC faculty. 
The selected students were welcomed to the university in a "kickoff" event in which graduate and undergraduate students presented their perspectives on research experiences, followed by a poster session comprised of over forty graduate students from fourteen labs across the College of Engineering at Drexel University. In the first week of the program, students independently researched labs and were interviewed by faculty mentors from across the university, leading to an informed selection of minimum three candidate labs of their choosing (Figure 1). Following the pairing of a student with a particular faculty/research lab, each participating student was further appointed a graduate student as a mentor to model the role of a research scientist and guide technical work. Once formally affiliated with a university lab and faculty/graduate student mentors, the students had to critically review relevant literature to first draft an abstract (within the first week of the program) and later formulate an independent research proposal (presented in Week 4) that would become the basis for their work throughout the program (Figure 1). Students selected research groups and projects based their own interests. In the first two years of this program, students have focused on topics such renewable energy, bio-inspired robotics, smart textiles, manufacturing of pharmaceuticals, and informatics. Students were financially compensated for their work (at no expense to the faculty advisors participating each year), which was, therefore, considered a full-time occupation over the ten week period.

The entire program was structured so that it creates a collaborative microenvironment, in which students interacted with each other, their individual mentors, the "teaching assistants", and the overall program coordinator (also a faculty in a STEM field). Weekly group meetings were typically comprised of a "mini-lecture" given by the program coordinator on topics such as what is research, how does conduct a literature review, etc., providing a venue for students to feel that they belong to a "summer class". Several invited guest speakers (predominantly faculty and staff) presented their views on contemporary drivers in STEM fields, such as advanced manufacturing and simulation-based science and engineering. In addition, students presented their individual research updates weekly (in the form of quad charts) so that the entire "class" could provide/receive constructive feedback.

Information literacy, the ability to quickly and efficiently find appropriate information for a problem at hand has been deemed the core literacy of the $21^{\text {st }}$ century ${ }^{(30,31)}$, reaching far beyond academic research. Librarians play a key role in teaching these skills ${ }^{(1)}$. Based on this fact, 
University library was fully integrated into the program's structure by introducing the students to key library professionals and providing short seminars on important digital resources and services. On the flip side, such active learning experiences provide librarians with more opportunities to engage students, adopt non-traditional roles for the profession, and develop collaborative relationships with faculty members ${ }^{(32)}$. Consequently and throughout the program, the liaison librarian for engineering remained an integral teaching partner, providing research support, feedback on students' literature reviews, writing and presentation rehearsals. This concept is referred to as Embedded Librarianship, in which a librarian embeds him or herself into the daily functions of a working group ${ }^{(33)}$. Library guides, online tutorials, instruction sessions and feedback from the librarian on presentations and papers provided valuable insights to students in structuring their research, organizing and reporting their results, supporting the aim of life-long learning (34).

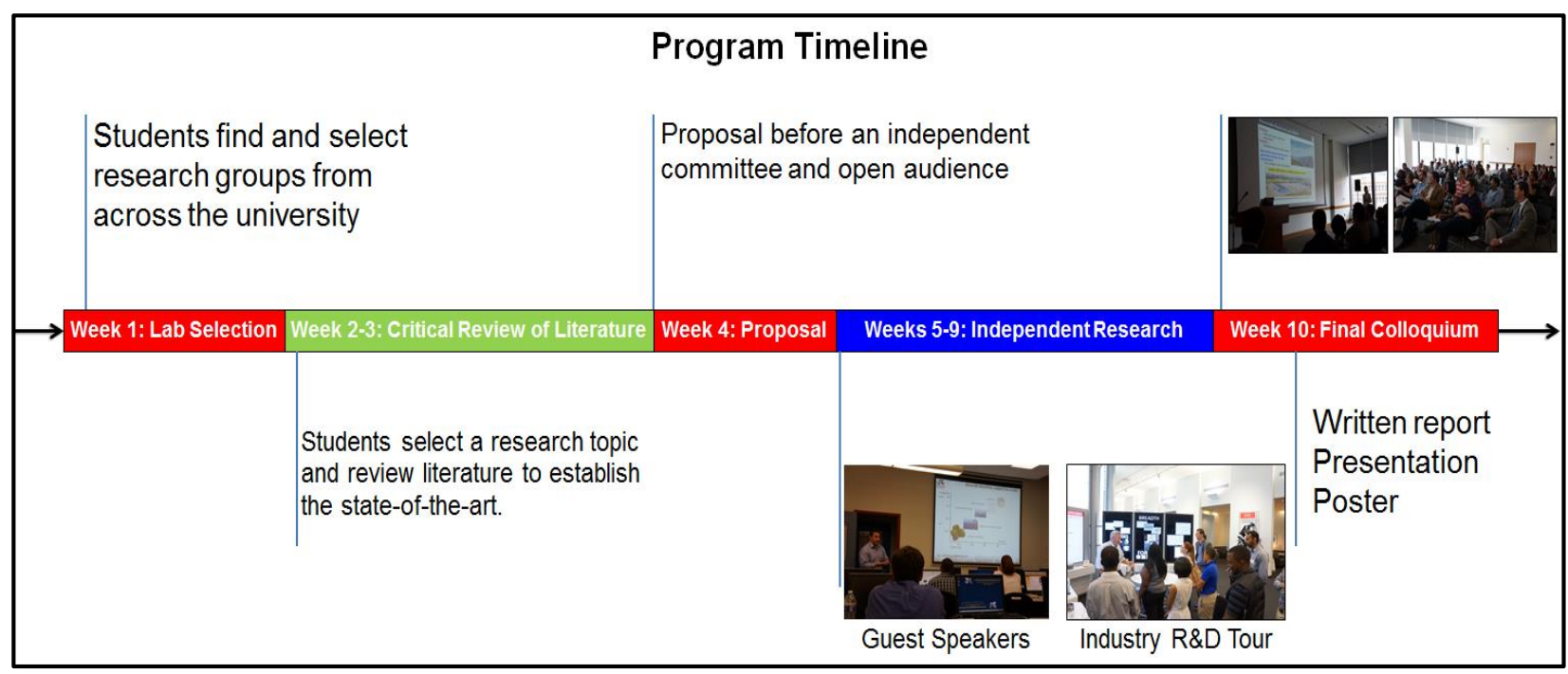

Figure 1: A schematic depicting the ten-week research program timeline.

\section{Results \& Discussion}

The students experienced the core functions of a research scientist, from finding a lab to formulating a research proposal, executing the research and presenting the results in written, poster, and slide presentation forms. Augmenting faculty and student mentors, the RISE coordinator and teaching assistants also provided individual feedback on writing ability at the abstract and literature review stages, as well as speaking/presentation in the proposal and final 
presentation stages. An improvement in writing and presentation skills of all students was observed from abstract to final report phase, partly reflected in quantitative scores provided by an independent panel of faculty judges for the midterm and final presentations.

The RISE students became progressively integrated into their research groups, gaining autonomy in their labs over the 10 week period. In addition, participants universally expressed increased interest in STEM education and subsequent careers, and reported a sense of "belonging" to their chosen labs, which can be interpreted as academic integration. A deliberate effort was further made to include the RISE students in concurrent departmental seminars, senior design presentations, Masters and PhD defenses in addition to selected visits to university courses and labs to shape their perspective on the typical level and amount of work at a research university. As a result, in both years, several students voluntarily worked in their labs beyond the official ten week duration. Moreover, to supplement the university research experience a one day visit to a corporate $R \& D$ facility was planned, where students were able to informally discuss various STEM career paths with experienced industry professionals.

To objectify and quantify some of the results produced by the implementation of this STEM program, the students were asked upon the program completion to assess the educational impacts of the several components of the program in addition to indicate their assessment on the likelihood to pursue a STEM career. On a response scale from 1-10 (very unlikely to very likely), students highly rated their likelihood to pursue STEM careers as shown in Figure 2. In the previous two years, the participating students collectively gave ratings ranging from 8-10 in response to this question.

A sampling of student testimonials to the experience is provided next.

In the RISE summer program I was gifted with the experience to work with undergraduate students, graduate students and professors in an academic research environment. I gained very important skills as far as talking to professionals, presentation skills and real experience in research. This program exceeded all of my expectations and left me with a bounty of knowledge and experience."

The RISE summer program consisted of 10 weeks of intensive exposure to the laboratory environment of our choice. In my case, the first few weeks were spent becoming accustomed to the research topic as well as learning the inner-workings of the lab. I had a PhD mentor who explained to me what needed to be completed in the lab. As time progressed, my reliance on the PhD mentor lessened and laboratory time seemed a bit more like independent study. 
My experience was a challenging one but also a great one! I was exposed to aspects of electrochemistry and go to develop my own protocols for my research. The challenge for my research was creating a protocol that would run successfully. I near the end developed a protocol, but did not get the desired results for my research even though the protocol was one that worked. Not getting the results that I expected made me learn that that is in fact a reality of a career in research. A researcher may do lots of work and still get unexpected results.

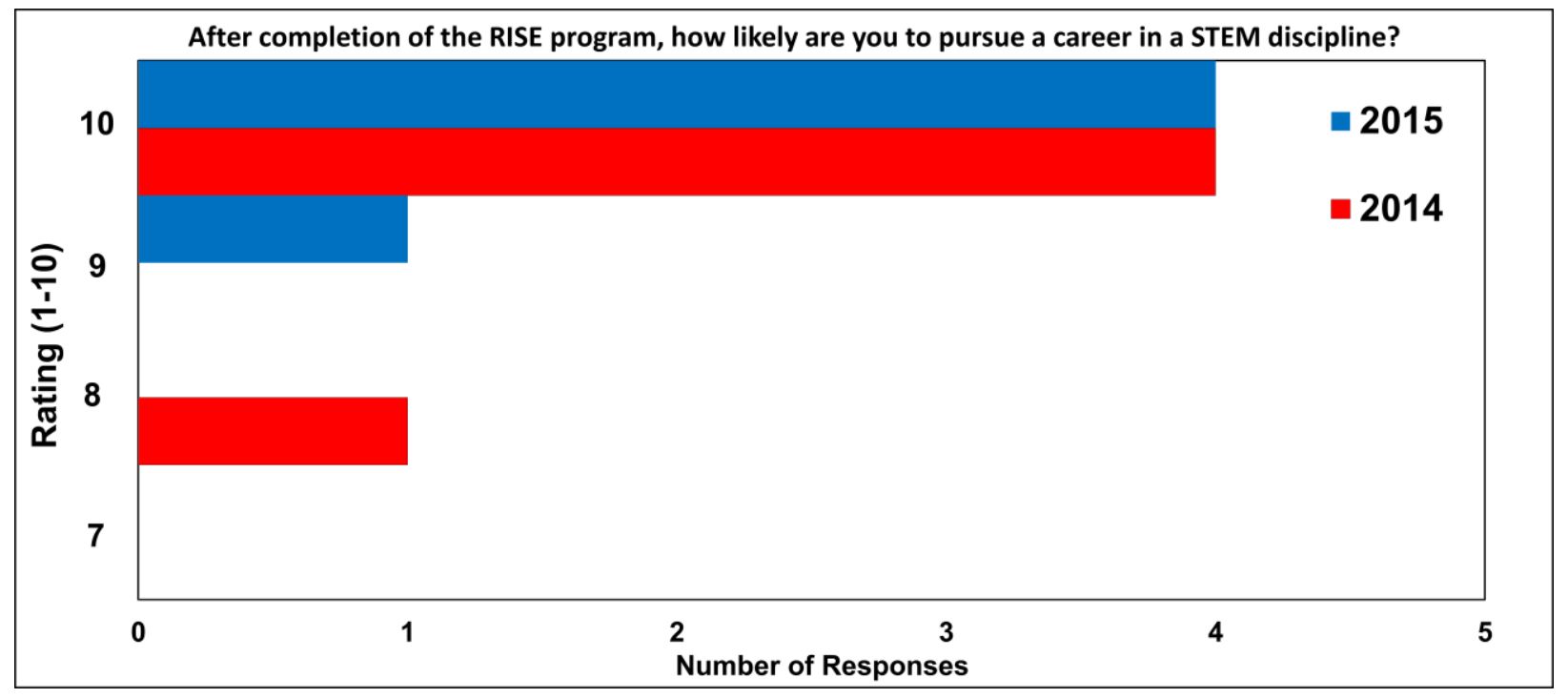

Figure 2: Students' self-reported likelihoods to pursue STEM careers

In Figure 3, the students' ranking of the most beneficial elements to their overall experience are provided. From this data, the most beneficial components are the selection of a lab/research, direct collaboration with faculty and graduate students, resources provided by the program coordinator, and the final colloquium experience. Their selections align well with current understanding of what makes undergraduate research a powerful educational experience.

Furthermore, strong mentoring relationships are considered an overwhelmingly positive element of successful undergraduate research experiences ${ }^{(1,21,22,24)}$. To capture the graduate student mentors' perspective, the participating mentors also provided feedback for this program. Overall, the mentors reported that they had to devise strategies to introduce broad fundamental concepts in a clear, yet compressed way - a more challenging and rewarding experience than typical teaching assistantships. In general, they observed a progression in their students from hesitant to increasingly confident and independent researchers. They further regarded their students as members of their own groups, facilitating academic integration. Below are some views expressed by the graduate student mentors. 


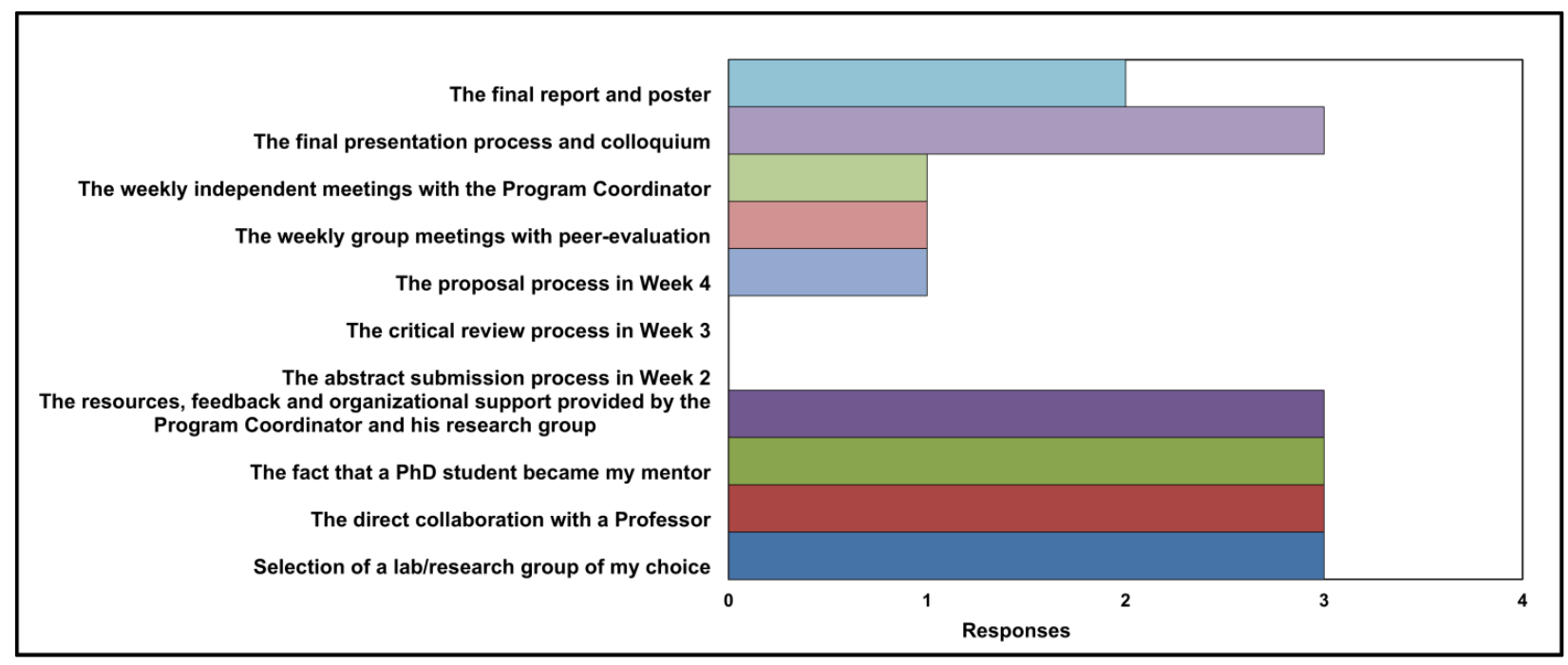

Figure 3: Students' selection of the most beneficial program elements, based solely on the 2015 cohort.

My experience was enlightening. Since he had not even taken an electric circuits course yet, I had to figure out a way to take him from calculus all the way to micro grid power systems. While I do have experience as a TA, conveying a streamlined chain of explanation over about 5 courses worth of material is something I would never have to undertake as a TA.

My student gained a lot of confidence over the summer - initially she was very hesitant to touch anything in the lab without explicit instruction, and by the end of the summer she was able to debug an experimental setup and was comfortable varying experimental parameters in complete independence.

The results of this program to date demonstrate that student mentors can have a mutually beneficial mentor and mentee experience by engaging in such research-based learning. In many cases, graduate student mentors have had more face to face interactions with their mentees than the supervising faculty. It has been our experience that students who would otherwise be reluctant to bring an issue to a faculty member are more likely to discuss it with their graduate student mentor, who can then take the appropriate action to resolve a particular issue. Furthermore, as a testimonial to the embedded librarian approach, our students came to view the engineering librarian as an additional mentor they could turn to at any point in the program. The librarian actively engaged the RISE students as they critical reviewed literature, prepared presentations, and composed their final research reports.

One year after program completion, the inaugural cohort of six students (four responding) was surveyed to monitor their educational progress. At the time of writing, two were still enrolled at $\mathrm{CC}$ of Philadelphia, one had dropped out of a four-year institution citing financial constraints, and 
one was enrolled in a four-year institution. Even in the "dropout" case, motivation to engage in STEM activity remained evident in this student's responses.

\section{Concluding Remarks}

Through a research-based learning approach, students were introduced to foundational research methods (e.g. conducting literature reviews, design of experiments, writing and presenting scientific work) which they immediately applied to their individual research projects from proposal to presentation phase. In the process, the students also gained familiarity with the university environment - which may lead to improved transfer outcomes. Integration into the academic environment was a key component of the RISE summer program. The overall experience created a collaborative microenvironment, fostering formal and informal faculty, student, and staff interaction and inclusion in university events - instilling a sense of "belonging" among URM and female students. Meeting the challenges of independent research further built self-confidence and reaffirmed ambitions for continued STEM education, with some of the students explicitly targeting doctoral degrees. The program models how teams of faculty, professional staff, and graduate students can transcend departmental and institutional boundaries to form strong collaborative partnerships that encourage STEM education. Results from years one and two of this project support the research-based learning approach as an enabler for engaging minority and female students in STEM.

\section{Acknowledgements}

The authors acknowledge the financial support received in the framework of the United States Department of Education's Minority Science and Engineering Improvement Program to implement this summer program.

\section{References}

[1] "Engage-to-Excel: Producing One Million Additional College Graduates with Degrees in Science,Technology, Engineering, and Mathematics," Executive Office of the President Washington, D.C.2012.

[2] C. Vest, "The Image Problem for Engineering," The Bridge vol. 41, pp. 5-11, 2011.

[3] S.-A. Allen-Ramdial and A. G. Campbell, "Reimagining the Pipeline Advancing STEM Diversity, Persistence, and Success," Bioscience, vol. 64, pp. 612-618, 2014.

[4] NAS, NAE, and IOM, "Rising Above the Gathering Storm," National Academy of Sciences2007. 
[5] N. Bell, S. Brainard, P. Campbell, M. Coomes, E. Derrick, M. Gomez, et al., "In Pursuit of a Diverse Science, Technology, Engineering, and Mathematics Workforce: Recommended Research Priorities to Enhance Participation by Underrepresented Minorities," American Association for the Advancement of Science National Science Foundation, 2001.

[6] "Expanding Underrepresented Minority Participation: America's Science and Technology at the Crossroads," National Academy of Sciences, Washington, D.C. 2011.

[7] S. Hurtado, C. B. Newman, M. C. Tran, and M. J. Chang, "Improving the rate of success for underrepresented racial minorities in STEM fields: Insights from a national project," New Directions for Institutional Research, vol. 2010, pp. 5-15, 2010.

[8] N. S. Board, "Science and Engineering Indicators 2014," ed. Arlington VA, 2014.

[9] M.-E. Reyes, "Unique Challenges for Women of Color in STEM Transferring from Community Colleges to Universities," Journal of College Science Teaching, vol. 81, pp. 241-263, 2011.

[10] D. L. Jackson and F. S. Laanan, "The role of community colleges in educating women in science and engineering," New Directions for Institutional Research, vol. 2011, pp. 39-49, 2011.

[11] W. G. Bowen, M. M. Chingos, and M. S. McPherson, Crossing the Finish Line: Completing College at America's Public Universities. Princeton, New Jersey: Princeton University Press, 2011.

[12] E. T. Pascarella and P. T. Terenzini, How College Affects Students: A Third Decade of Research, Volume 2: Jossey-Bass, 2005.

[13] B. K. Townsend and K. Wilson, "'A Hand Hold for A Little Bit": Factors Facilitating the Success of Community College Transfer Students to a Large Research University," Journal of College Student Development, vol. 47, pp. 439-456, 2006.

[14] B. K. Townsend, "“Feeling like a freshman again": The transfer student transition," New Directions for Higher Education, vol. 2008, pp. 69-77, 2008.

[15] A. C. Dowd, J. Cheslock, and T. Melguizo, "Transfer access from community colleges and the distribution of elite higher education," Journal of Higher Education, vol. 79, pp. 1-31, 2008.

[16] B. K. Townsend, "The outlook for transfer programs and the direction of the community college," New Directions for Community Colleges, vol. 2009, pp. 103-110, 2009.

[17] L. E. Eggleston, S. S. Starobin, and F. S. Laanan, "Adjustment of Community College Students at a Four-Year University: Role and Relevance of Transfer Student Capital for Student Retention," Journal of College Student Retention: Research, Theory and Practice, vol. 12, pp. 175-209, 2010.

[18] D. L. Jackson, S. S. Starobin, and F. S. Laanan, "The Shared Experiences: Facilitating Successful Transfer of Women and Underrepresented Minorities in STEM Fields," New Directions for Higher Education, vol. 2013, pp. 69-76, 2013.

[19] S. J. Handel and R. A. Williams, "The Promise of the Transfer Pathway: Opportunity and Challenges for Community College Students Seeking the Baccalaureate Degree," 2012.

[20] S. Hurtado, N. Cabrera, M. Lin, L. Arellano, and L. Espinosa, "Diversifying Science Underrepresented Student Experiences in Structured Research Programs," Research in Higher Education, vol. 50, 2009.

[21] M. K. Eagan, Jr., S. Hurtado, M. J. Chang, G. A. Garcia, F. A. Herrera, and J. C. Garibay, "Making a Difference in Science Education: The Impact of Undergraduate Research Programs," Am Educ Res J, vol. 50, pp. 683-713, Aug 2013.

[22] S. S. Kenny, B. Alberts, W. Booth, M. Glaser, M. Glassick, S. O. Ikenberry, et al., "Reinventing Undergraduate Education: A Blueprint for America's Research Universities.," State University of New York: Boyer Commission on Educating Undergraduates in the Research University, Stony Brook, NY1998. 
[23] N. Balster, C. Pfund, R. Rediske, and J. Branchaw, "Entering Research: A Course That Creates Community and Structure for Beginning Undergraduate Researchers in the STEM Disciplines," CBE Life Sciences Education, vol. 9, pp. 108-118, 2010.

[24] N. Hensel, "Characteristics of Excellence in Undergraduate Research," The Council on Undergraduate Research, Washington, D.C.2012.

[25] J. L. Linley and C. E. George-Jackson, "Addressing Underrepresentation in STEM Fields through Undergraduate Interventions," New Directions for Student Services, vol. 2013, pp. 97-102, 2013.

[26] S. H. Russell, M. P. Hancock, and J. McCullough, "Benefits of Undergraduate Research Experiences," Science, vol. 316, pp. 548-649, 2007.

[27] D. Christe, A. Shah, J. J. Bhatt, M. R. Mergenthal, L. Powell, and A. Kontsos, "Raising Interest in STEM Education: A Research-based Learning Framework for Improving Minority Participation," presented at the 122nd American Society for Engineering Education Annual Conference \& Exhibition, Seattle, WA, 2015.

[28] S. Snyder, "New Phila. campaign aims to increase college graduation rate. ," in The Inquirer, ed. Philadelphia, PA, 2010.

[29] (2015, 10 April 2015). Key Facts. Available: http://www.ccp.edu/about-us/key-facts

[30] "Presidential Committee on Information Literacy: Final Report," 1989.

[31] (2015). Information Literacy. Available: http://www.unesco.org/new/en/communication-andinformation/access-to-knowledge/information-literacy/

[32] M. Fosmire, "Information literacy and engineering design: Developing an integrated conceptual model," IFLA Journal, vol. 38, pp. 47-52, 2012.

[33] D. Shumaker, The Embedded Librarian: Innovative Strategies for Taking Knowledge Where It's Needed, 2012.

[34] "Criteria for Accrediting Engineering Programs," ed. Baltimore, Maryland: Accreditation Board for Engineering and Technology, 2014. 